\title{
Knockdown of IncRNA TUG1 inhibits hippocampal neuronal apoptosis and participates in aerobic exercise-alleviated vascular cognitive impairment
}

\author{
Jing Wang ${ }^{1 \dagger}$, Yali Niu ${ }^{1 \dagger}$, Huaying Tao ${ }^{2}$, Mina Xue ${ }^{3}$ and Chunxiao Wan ${ }^{1 *}$
}

\begin{abstract}
Objectives: Our previous study indicated that aerobic exercise relieves cognitive impairment in patients with vascular cognitive impairment ( $\mathrm{VCl}$ ) via regulating brain-derived neurotrophic factor (BDNF), but the mechanism is not yet clear. This study aimed to explore whether IncRNA taurine upregulated gene 1 (TUG1) participates in the process of $\mathrm{VCl}$ by regulating BDNF.

Methods: The expressions of TUG1 and BDNF in the serum of VCl patients were detected. The potential molecular mechanisms of TUG1 in regulating hippocampal neuronal apoptosis were explored in oxygen and glucose deprivation-induced (OGD-induced) hippocampal cell line HT22. The VCI mouse model was established, and TUG1 and BDNF were overexpressed via lentivirus injection. The cognitive impairment of mice was detected by the Morris water maze experiment after the aerobic exercise.

Results: The level of TUG1 was elevated in the serum of VCl patients compared with the control group. The knockdown of TUG1 in OGD-induced HT22 cells increased BDNF level and decreased cell apoptosis, and the downregulation of BDNF restored the decreased cell apoptosis. RNA immunoprecipitation and RNA pull-down assays showed that TUG1 could bind to BDNF protein. The aerobic exercise alleviated cognitive impairment and inhibited hippocampal apoptosis in VCl mice. Meanwhile, the overexpression of TUG1 reversed the therapeutic effects of aerobic exercise on cognitive impairment.
\end{abstract}

Conclusions: The knockdown of TUG1 reduced hippocampal neuronal apoptosis and participates in the aerobic exercise-alleviated $\mathrm{VCl}$, which was partly through regulating BDNF.

Keywords: Vascular cognitive impairment, IncRNA TUG1, BDNF, Aerobic exercise

\footnotetext{
*Correspondence: Chunxiaowan_wxc@163.com

†Jing Wang and Yali Niu contributed equally to this work and should be regarded as co-first authors

${ }^{1}$ Department of Physical and Rehabilitation Medicine, Tianjin Medical University General Hospital, No. 154 Anshan Road, Peace District, Tianjin 300070, People's Republic of China

Full list of author information is available at the end of the article
}

\begin{abstract}
Introduction
Vascular cognitive impairment (VCI) is a cognitive impairment caused by vascular diseases, including mild cognitive impairment and dementia [1]. So far, the pathogenesis of VCI is not clear, and there is no effective treatment, which can only be prevented via treating vascular diseases and other VCI risk factors $[1,2]$. Studies have revealed that aerobic exercise improves cardiovascular function in adults and also improves cognitive performance in patients with VCI [3-5]. Nevertheless,
\end{abstract}

(c) The Author(s) 2020. This article is licensed under a Creative Commons Attribution 4.0 International License, which permits use, sharing, adaptation, distribution and reproduction in any medium or format, as long as you give appropriate credit to the original author(s) and the source, provide a link to the Creative Commons licence, and indicate if changes were made. The images or other third party material in this article are included in the article's Creative Commons licence, unless indicated otherwise in a credit line to the material. If material is not included in the article's Creative Commons licence and your intended use is not permitted by statutory regulation or exceeds the permitted use, you will need to obtain permission directly from the copyright holder. To view a copy of this licence, visit http://creativeco mmons.org/licenses/by/4.0/. The Creative Commons Public Domain Dedication waiver (http://creativecommons.org/publicdomain/ zero/1.0/) applies to the data made available in this article, unless otherwise stated in a credit line to the data. 
the mechanism by which aerobic exercise relieves $\mathrm{VCI}$ is unclear.

Long non-coding RNAs (lncRNAs) are widely involved in various human pathological processes, including cerebrovascular diseases [6]. For example, lncRNA SNHG1 and IncRNA MALAT1 have been identified to play a neuroprotective role in ischemic stroke [7, 8]. LncRNA taurine upregulated gene 1 (TUG1) is one of the earliest identified lncRNAs associated with human diseases, which plays a vital regulatory role in various diseases by regulating biological processes, such as cell proliferation, differentiation, and apoptosis [9-11]. Studies have shown that TUG1 may be related to the pathology of neurodegenerative diseases [12]. Nevertheless, it is not explicit whether TUG1 is involved in the pathology of VCI.

Brain-derived neurotrophic factor (BDNF), an important member of the family of neurotrophic factors, is essential for the development of the nervous system and is closely related to neuropathology [13, 14]. We have found that aerobic exercise can alleviate VCI through BDNF [15]. Moreover, we found that TUG1 and BDNF protein may have binding sites through bioinformatics, suggesting that there may be an interaction between TUG1 and BDNF.

This current study aimed to explore whether TUG1 could participate in the pathological process of $\mathrm{VCI}$ through regulating BDNF and participate in the process of aerobic exercise-alleviated VCI.

\section{Materials and methods}

\section{Serum specimens}

Fasting venous blood $4 \mathrm{~mL}$ was collected from 20 healthy and $20 \mathrm{VCI}$ patients at 9-11 a.m., and serum was collected by centrifugation and stored at $-80{ }^{\circ} \mathrm{C}$ for later use. It was found no significant difference in the basic characteristics of the involved patients $(p>0.05$, Table 1$)$. All VCI patients and healthy volunteers have signed informed consent, and all human subjects were obtained following ethics committee guidelines and regulations of Tianjin Medical University General Hospital.

\section{ELISA analysis}

The blood was natural coagulation at room temperature for $20 \mathrm{~min}$. The supernatant was collected by centrifugation at $1000 \mathrm{~g}$ at $4{ }^{\circ} \mathrm{C}$ for $10 \mathrm{~min}$. BDNF concentration was detected using the Human BDNF ELISA KIT (Solarbio, Beijing, China) according to the manufacturer's instructions.

\section{Cell culture and treatment}

Mouse hippocampal cell line HT22 was purchased from ATCC (Manassas, VA, USA). HT22 cells were cultured in Dulbecco's modified eagle medium (DMEM; Gibco, New York, USA) mixed with $1 \%$ penicillin-streptomycin (Gibco) and 10\% fetal bovine serum (FBS). The cells were maintained in a humidified incubator with $95 \%$ air and $5 \% \mathrm{CO}_{2}$ atmosphere at $37^{\circ} \mathrm{C}$.

Oxygen and glucose deprivation (OGD) treatment was used to induce the ischemic injury of HT22 cells. The cell culture medium was changed to glucose-free DMEM (Gibco) and the cells were incubated in a $95 \% \mathrm{~N}_{2}$ and $5 \%$ $\mathrm{CO}_{2}$ incubator at $37^{\circ} \mathrm{C}$ for $1 \mathrm{~h}$. The cell culture medium was replaced with a normal medium containing FBS, and the cells were then cultured at $37{ }^{\circ} \mathrm{C}$ with air $\left(21 \% \mathrm{O}_{2}\right)$ and $5 \% \mathrm{CO}_{2}$ for $24 \mathrm{~h}$.

\section{Cell transfection}

The sh-TUG1, sh-BDNF, and control shRNA (GenePharma) were constructed into a lentiviral vector and then packaged into lentiviral particles (GenePharma). HT22 cells were infected with the lentivirus $\left(5 \times 10^{5} \mathrm{TU}\right.$ per 24-well plate) for $72 \mathrm{~h}$ before OGD treatment. The shRNA sequences were shown as follows:

sh-NC: sense $5^{\prime}$-UUCUCCGAACGUGUCACGUTT$3^{\prime}$, antisense 3'-ACGUGACAC GUUCGGAGAATT-5'.

sh-TUG1: sense 5'-CCAUCUCACAAGGCUUCA ATT-3', antisense $3^{\prime}$-TTGGUAG AGUGUUCCGAAG UU-5'.

sh-BDNF: sense 5'-GGTGATGCTCAGCAGTCA AGT-3', antisense 3'-CCACTACG AGTCGTCAGTTC A- $5^{\prime}$.

\section{Quantitative real-time PCR (qRT-PCR)}

The total RNA of serum, mouse hippocampus tissue, or HT22 cells was isolated using Trizol reagent (Invitrogen, Carlsbad, CA, USA). cDNA was synthesized by the PrimeScript RT Master Mix (Takara, Dalian, China) with $0.1 \mu \mathrm{g}$ of total RNA. The levels of TUG1 and

Table 1 Basic characteristics of the patients involved in this study

\begin{tabular}{|c|c|c|c|c|}
\hline \multirow[t]{2}{*}{ Groups } & \multicolumn{2}{|l|}{$\operatorname{Sex}(n)$} & \multirow{2}{*}{$\begin{array}{l}\text { Age } \\
\text { (mean } \pm S D \text {, year) }\end{array}$} & \multirow{2}{*}{$\begin{array}{l}\text { BMI } \\
\left(\text { mean } \pm S D, k g / \mathrm{m}^{2}\right)\end{array}$} \\
\hline & Male & Female & & \\
\hline Healthy $(n=20)$ & 11 (55\%) & $9(45 \%)$ & $66.37 \pm 7.29$ & $23.09 \pm 1.50$ \\
\hline $\operatorname{VCl}(n=20)$ & 10 (50\%) & $10(50 \%)$ & $65.69 \pm 8.17$ & $23.51 \pm 0.97$ \\
\hline
\end{tabular}

$\mathrm{VCl}$ vascular cognitive impairment, SD standard deviation, $B M I$, body mass index 
BDNF mRNA was detected by the SYBR Premix Ex Taq (TaKaRa) and ABI 7500 Real-Time PCR system (Applied Biosystems, Carlsbad, USA). $\beta$-actin was used as an internal control. The qRT-PCR primers were shown as follows:

TUG1: (F) 5'-CTGAAGAAAGGCAACATC-3', (R) 5'-GTAGGCTACTACAGGAT TTG-3'.

BDNF mRNA: (F) 5'-AGGACAGCAAAGCCACAA TGTTCC-3', (R) 5'-TGGACG TTTGCTTCTTTCATG GGC-3'.

$\beta$-actin: (F) 5'-TGAGAGGGAAATCGTGCGTGAC-3', (R) 5'-AAGAAGGAAGGC TGGAAAAGAG-3'.

\section{Western Blot}

HT22 cells or mouse hippocampus tissue were lysed using RIPA lysis buffer (Beyotime, Shanghai, China). The BCA Kit (Beyotime) was used to detect protein concentration. Equal amounts of protein lysate were used for SDS-PAGE and transferred the protein to the PVDF membrane (Millipore, Bedford, USA) via electro-transfer [16]. Then, the PVDF membrane was blocked using QuickBlock ${ }^{\mathrm{TM}}$ Blocking Buffer (Beyotime) and incubated overnight with the Anti-BDNF antibody (ab108319,1:1000) and the Anti- $\beta$ actin antibody (ab8227, 1:1000). After that, the second antibody was incubated for $3 \mathrm{~h}$ at $4{ }^{\circ} \mathrm{C}$. The membranes were detected using the ECL system (Beyotime). $\beta$-actin was used as a control for total protein amount.

\section{Flow cytometry}

HT22 cells or slices of mouse hippocampal tissues were detected apoptosis using the Annexin V-FITC Apoptosis Detection Kit (Solarbio Life Sciences, Beijing, China) according to the manufacturer's instructions. Briefly, $3 \mathrm{~mL}$ Binding Buffer $(10 \times)$ was diluted to $30 \mathrm{~mL}$ with $27 \mathrm{~mL}$ of deionized water. Cells $\left(1 \times 10^{6}\right)$ were collected and washed with cold phosphate buffer saline (PBS). Then, cells were suspended in $1 \mathrm{~mL} 1 \times$ Binding Buffer, followed by the centrifugation at $300 \times g$ for $10 \mathrm{~min}$ before discarding the supernatant. Cells were resuspended with $1 \mathrm{~mL} 1 \times$ Binding Buffer to make the cell density reach $1 \times 10^{6}$ cells $/ \mathrm{mL}$. Cells with $100 \mu \mathrm{L}\left(1 \times 10^{5}\right)$ were added to each tube. Then, $5 \mu \mathrm{L}$ Annexin V-FITC was added to the tube for the mixture of $10 \mathrm{~min}$ at room temperature in dark. After that, $5 \mu \mathrm{L}$ PI was added and the cells were cultured for $5 \mathrm{~min}$ at room temperature in dark. After being mixed with $500 \mu \mathrm{L}$ PBS, the cells were applied to detect apoptosis using the flow cytometer (FACSCanto II; BD Biosciences, San Jose, CA, USA).

\section{Cell viability assay}

Cell viability was detected using the MTT (3-(4, 5-dimethylthiazol-2-yl)-2, 5-diphenyl-2H-tetrazol-3-ium bromide) Cell Proliferation and Cytotoxicity Assay Kit
(Solarbio Life Sciences, Beijing, China). In brief, the log phase cells were collected and the cell suspension concentration was adjusted. Then, the cells were seeded into 96-well plates with $180 \mu \mathrm{L}$ per well (3000-10,000 cells/ well). The cells were placed in a $37^{\circ} \mathrm{C}, 5 \% \mathrm{CO}_{2}$ incubator for 6-24 h. After carefully aspirating the supernatant, we added $90 \mu \mathrm{L}$ of fresh culture medium, followed by adding $10 \mu \mathrm{L}$ of MTT solution and continued to incubate cells for $4 \mathrm{~h}$. Then, $110 \mu \mathrm{L}$ of Formazan dissolving solution was added to each well and the cells were placed on a shaker at low speed for $10 \mathrm{~min}$. The absorbance of each well at $490 \mathrm{~nm}$ was measured in an enzyme-linked immunoassay instrument (JK-MR-5031, JK Imaging, CA, USA).

\section{RNA pull-down assay}

The biotinylated DNA probe complementary of TUG1 (sense) and biotin-labeled antisense TUG1 (anti-sense) were synthesized (Genepharma). Sense or anti-sense was purified and transfected into HT22 cells. After $48 \mathrm{~h}$, the cells were collected. RNA pull-down assays were performed using the Pierce Magnetic RNA-Protein PullDown Kit (Thermo Scientific, Waltham, MA, USA) according to the manufacturer's instructions. The level of BDNF in the complex was detected via Western Blot.

\section{RNA immunoprecipitation (RIP) assay}

HT22 cells were collected using RIPA lysis buffer (Beyotime). RIP assay was performed using the Magna RIP RNA-Binding Protein Immunoprecipitation Kit (Millipore) and anti-BDNF or IgG (Millipore). The level of TUG1 in the complex was detected via qRT-PCR.

\section{Animals}

C57BL/6 male mice (6-7 weeks old) were purchased from the Charles River (Beijing, China), and were kept in light/dark cycle for $12 \mathrm{~h}$ at $22-25{ }^{\circ} \mathrm{C}$ for free feeding. All animal experiments used in this study were approved by the Animal Ethical Committee of the Tianjin Medical University General Hospital.

\section{$\mathrm{VCl}$ mouse model}

The VCI mouse model (the 2VO group) was established by ligating bilateral common carotid arteries (CCAs) according to the previous description [17]. In brief, mice $(n=6)$ were anesthetized with $10 \%$ chloral hydrate $(400 \mathrm{mg} / \mathrm{kg}$, intraperitoneal injection). The bilateral CCAs were ligated with $4-0$ silk sutures for $20 \mathrm{~min}$. The sutures were removed and the bilateral CCAs were visually inspected for reperfusion at the end of the occlusion period. The bilateral CCAs were again ligated for $20 \mathrm{~min}$ after the blood flow was restored for $10 \mathrm{~min}$. The occlusion and the reperfusion were repeated three times. Bilateral CCAs of mice in the Sham group were not ligated. 
Lentiviral TUG1 overexpression vector (LentiTUG1) and lentiviral vector (Lenti-control) containing a sequence of scrambled control were designed, packaged, and purified by GenePharma (Shanghai, China). Mice were injected with Lenti-TUG1 or Lenti-control via bilateral ventricles. Mice underwent aerobic exercise via an animal treadmill and mice performed $30 \mathrm{~min}(12 \mathrm{~m} /$ min) treadmill exercise every day (5 days a week) for 4 weeks [18]. The Morris water maze experiment was then performed. After the Morris water maze experiment, mice were sacrificed, and the brains were collected. Hippocampal tissues were quickly separated on ice, and the tissues were made into $10 \%$ tissue homogenate for further experiments.

\section{The Morris water maze experiment}

The Morris water maze was used to assess cognitive impairment in mice using the previously described method $[19,20]$. In brief, the circular pool was filled with about $25^{\circ} \mathrm{C}$ of water and maintain the temperature. Then, the mice were trained for 4 days to find the platform. After that, skimmed milk powder was added to make the water opaque. The time at which mice found the platform was recorded, and if it exceeded $60 \mathrm{~s}$, it was recorded as $60 \mathrm{~s}$. Performing five times a day for a total of 5 days. After the Morris water maze was completed, the mouse was sacrificed and hippocampal tissue was collected for subsequent studies.

\section{Statistical analysis}

Statistics were calculated via SPSS 22.0 (Chicago, IL, USA), and all data were presented as mean \pm standard deviation (SD). The difference among multiple groups was compared via the one-way analysis of variance (ANOVA) followed by the LSD post hoc test. The difference between the two groups was compared via the Student's t-test. The $P$-value $<0.05$ was considered statistically significant.

\section{Results}

Aberrant expression of TUG1 and BDNF in the serum of VCI patients

To investigate whether TUG1 and BDNF were differentially expressed during VCI, we detected the levels of TUG1 and BDNF in the serum of healthy people $(n=20)$ and VCI patients $(n=20)$. The results of qRT-PCR showed that compared with healthy people, the level of TUG1 was observably elevated in the serum of VCI patients, which was 2.9 times higher than that in healthy people (Fig. 1a), while the mRNA level of BDNF was 0.52 times lower than that in healthy people (Fig. 1b). Meanwhile, ELISA results showed that serum BDNF levels

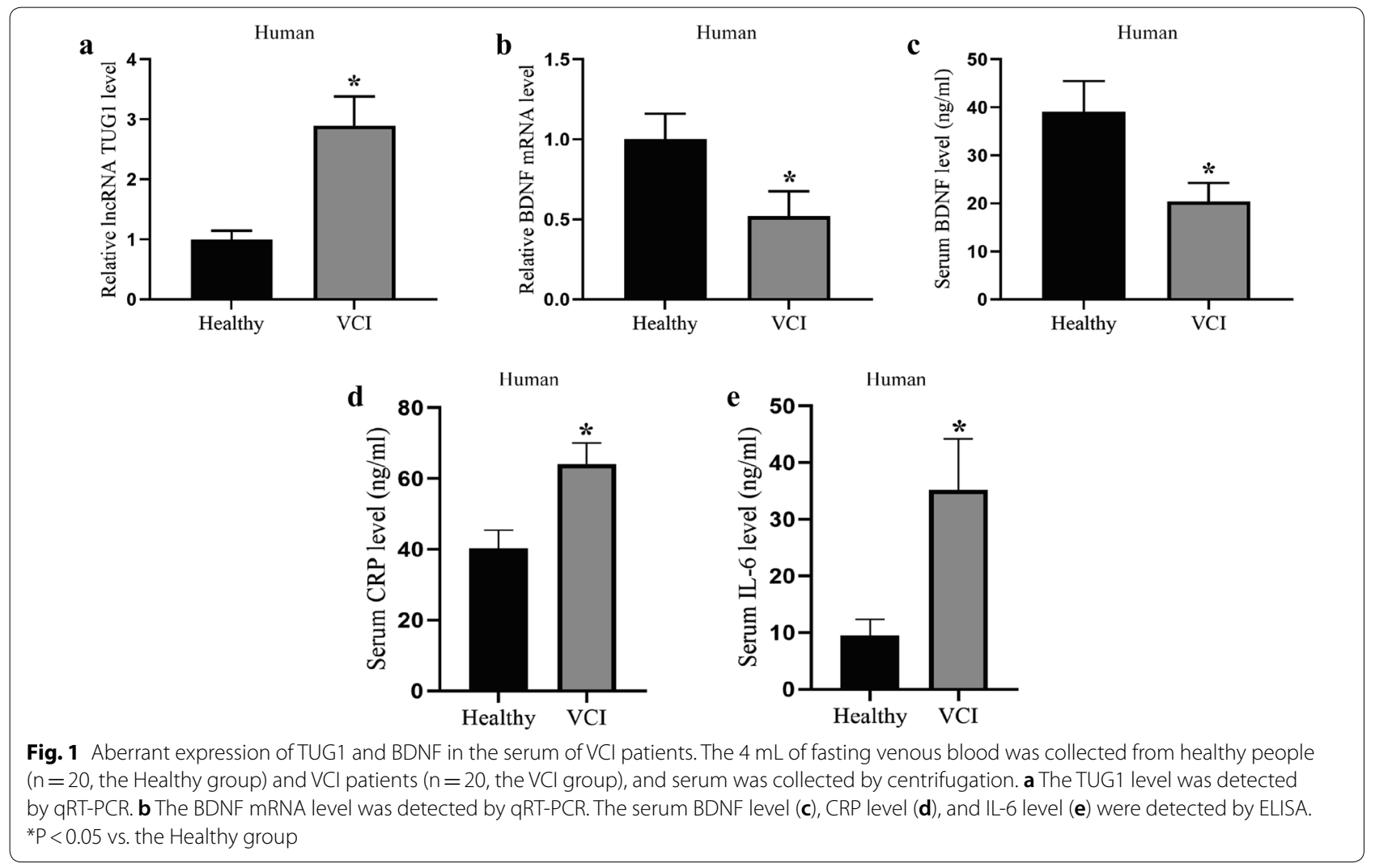


were markedly reduced in VCI patients (Fig. 1c). Besides, the serum CRP (Fig. 1d) and IL-6 (Fig. 1e) levels in the VCI patients were upregulated in comparison with the healthy controls, indicating the brain injury of the VCI patients. These results indicated that TUG1 and BDNF may be involved in the pathological process of $\mathrm{VCI}$.

\section{TUG1 knockdown reduces the apoptosis of OGD-induced} hippocampal neurons

Murine hippocampal neuron cell line HT22 was treated with OGD to mimic VCI in vitro [15]. After the OGD treatment, the cell viability of HT22 cells was inhibited, which was partly reversed by the lentivirus-mediated TUG1 knockdown (Fig. 2a). In the OGD-treated HT22 cells, the level of TUG1 was increased (Fig. 2b), while the expression level of BDNF was decreased at mRNA levels (Fig. 2c), and these effects were negated by the lentivirus-mediated TUG1 knockdown. The cell apoptosis was elevated in OGD-induced HT22 cells with the increased expression of the pro-apoptotic marker (cleaved caspase 3 ) and the decreased expression of the anti-apoptotic marker (Bcl2) (Fig. 2d-g). Such promotive effects mediated by the OGD treatment were reversed by the lentivirus-mediated TUG1 knockdown (Fig. 2d-g). These

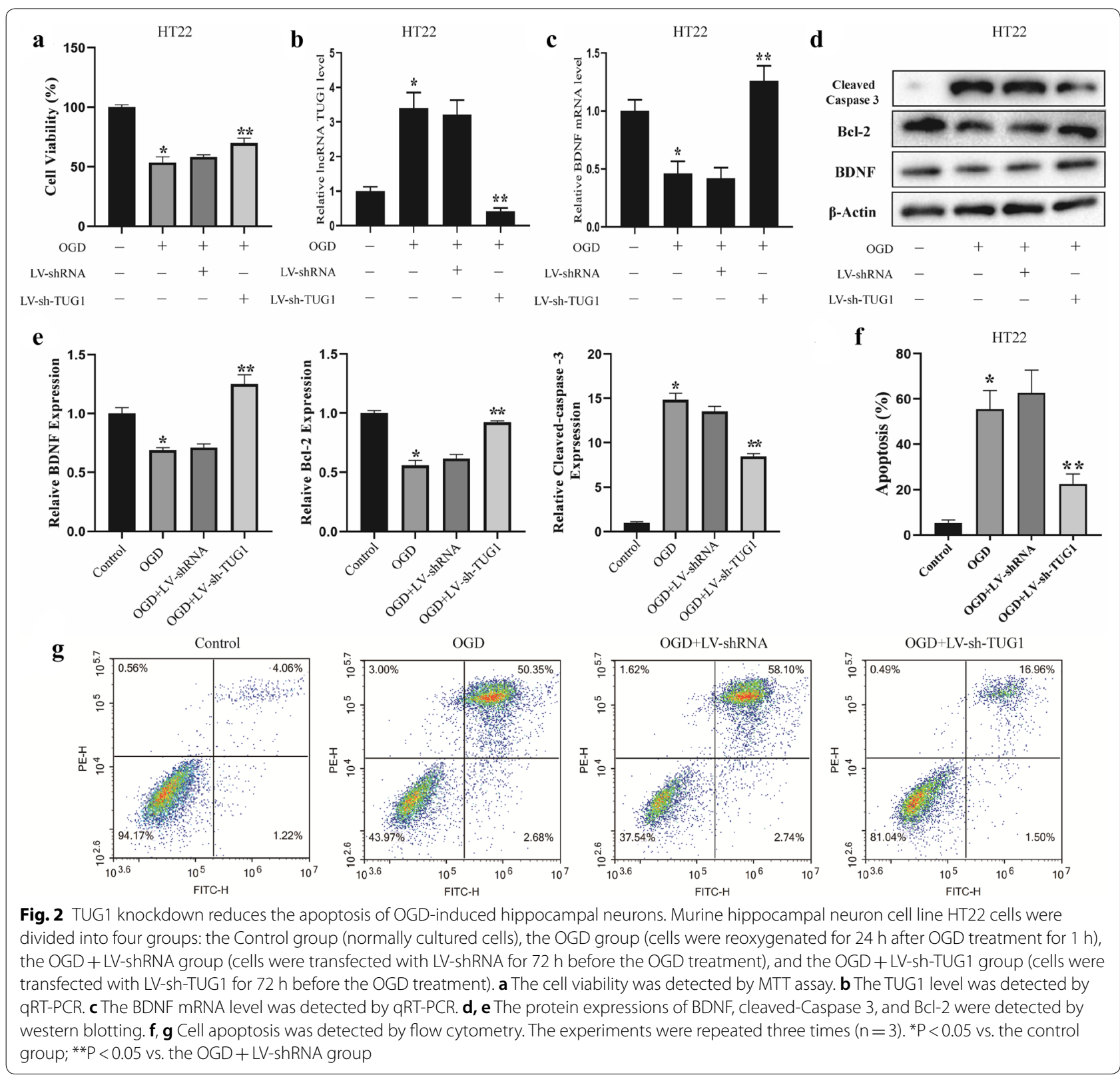


results suggested that TUG1 may regulate cell apoptosis in VCI.

\section{TUG1 knockdown reduces hippocampal neuronal apoptosis by upregulating BDNF}

To further explore the relationship between TUG1 and BDNF, we detected whether TUG1 binds to BDNF via RIP and RNA pull-down analysis. RIP results showed that TUG1 was enriched in the anti-BDNF immunoprecipitants (Fig. 3a), and BDNF was enriched in the TUG1pulled down compounds (Fig. 3b). These results indicated that TUG1 could bind to BDNF protein. Moreover, under the OGD treatment, the knockdown of TUG1 elevated mRNA and protein levels of BDNF, and the lentivirusmediated BDNF knockdown reversed such effect (Fig. 3c, d). Furthermore, the lentivirus-mediated BDNF knockdown reduced the elevation of cell apoptosis which was caused by TUG1 knockdown in OGD-induced HT22 cells (Fig. $3 \mathrm{e}-\mathrm{g}$ ). The trends of protein expressions of cleaved-Caspase 3 and Bcl-2 were consistent with the apoptotic results (Fig. 3e-g). These results indicated that TUG1 negatively regulates BDNF expression by binding to BDNF, thus affecting the apoptosis of OGD-induced hippocampal neurons.

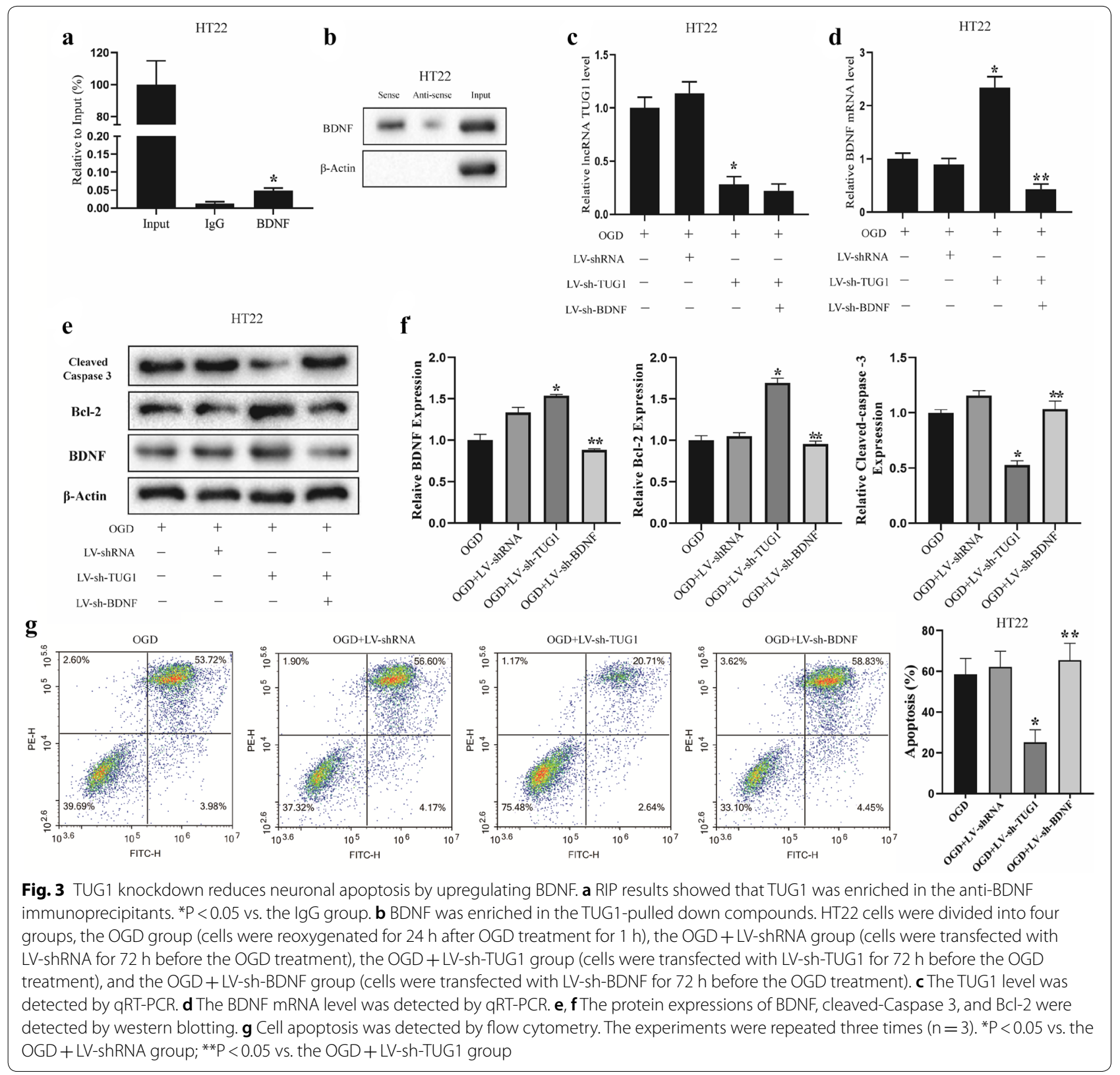




\section{Aerobic exercise alleviates mouse $\mathrm{VCl}$ via downregulating TUG1}

To further explore whether TUG1 participates in the therapeutic effect of aerobic exercise on VCI, Lenticontrol or Lenti-TUG1 were injected into the ventricle of the VCI mice, followed by the aerobic exercise for 4 weeks ( $n=6$ in each group). The $H \& E$ staining results showed that the brain tissues in the $2 \mathrm{VO}$ group presented hypoxic regions, while after the aerobic exercise for 4 weeks, the hypoxic regions were reduced. Besides, the overexpression of TUG1 negated the effect of the aerobic exercise (Fig. 4a). The Morris water maze test is widely used to detect spatial learning and memory in laboratory mice [21]. We used the Morris water maze test to evaluate the effects of TUG1 on the cognitive function of VCI mice. The results revealed that the latency to reach the platform was increased in the VCI mice compared with the sham mice, but after the aerobic exercise, the latency was reduced and such reduction was restored by the Lenti-TUG1 injection (Fig. 4b). Next, we collected hippocampal tissues, and the level of TUG1 in VCI mice was restored by the Lenti-TUG1 injection, which was reduced after the aerobic exercise (Fig. 4c). The LentiTUG1 injection also reduced the enhancement of the BDNF expression that was raised after the aerobic exercise (Fig. 4d). Besides, the Lenti-TUG1 injection restored the reduction of the apoptosis which was reduced after the aerobic exercise (Fig. $4 \mathrm{e}-\mathrm{h}$ ). The trends of protein expressions of cleaved-Caspase 3 and $\mathrm{Bcl}-2$ were consistent with the apoptotic results (Fig. $4 \mathrm{e}-\mathrm{h}$ ). These findings indicated that aerobic exercise alleviates mouse VCI partly via downregulating TUG1.

\section{Discussion}

Cognitive impairment of vascular etiology is the leading cause of dementia in East Asia and Western countries following Alzheimer's disease [22]. Vascular dementia is the most serious form of VCI [23]. Nevertheless, the molecular mechanism of VCI pathogenesis is poorly understood $[1,2]$. More and more studies have indicated that aerobic exercise can improve cognitive impairment including VCI [24], but the mechanism is not clear. In our previous study, we have found that aerobic exercise can alleviate VCI through upregulating BDNF [15]. In this study, we found that the expression of TUG1 was significantly elevated in the serum of VCI patients compared with healthy people. Moreover, knockdown of TUG1 inhibits hippocampal neuronal apoptosis by promoting the expression of BDNF in OGD-induced HT22 cells. Finally, we demonstrated that aerobic exercise can improve cognitive impairment and inhibit hippocampal apoptosis of VCI mice by downregulating TUG1 expression. Our findings provide a potential target for the treatment of $\mathrm{VCI}$ and provide new insights into the potential mechanism of the aerobic exercise-alleviated VCI.

Cerebral hypoperfusion is generally considered to be the underlying pathophysiological mechanism of VCI [25]. Model animal experiments have shown that cerebral hypoperfusion can cause white matter damage, brain atrophy, and memory impairment [25, 26]. Furthermore, About $30 \%$ of survivors with ischemic stroke will develop VCI or vascular dementia [27]. The cerebral hypoperfusion model is usually used as a VCI model. In this study, we established the mouse VCI model by ligating bilateral CCAs to mimic the cerebral hypoperfusion in vivo. The Morris water maze was used to determine the cognitive impairment of the VCI mice. We found that the knockdown of TUG1 can reduce hippocampal neuronal apoptosis in vitro and the overexpression of TUG1 can negate the anti-apoptotic effect of the aerobic exercise on VCI mice in vivo. Studies have shown that apoptosis can explain the neurocyte loss observed in many neurological diseases including VCI [28]. Thus, we used the in vitro model and the in vivo model to demonstrate the effect of TUG1 in hippocampal neuronal apoptosis-mediated VCI.

Many investigations indicate that aerobic exercise improves the function of the central nervous system, the attention, and the working memory, and reduces the risk of cognitive impairment and dementia [14, 29, 30]. Similarly, aerobic exercise can also alleviate VCI $[3,31]$. BDNF is the most common neurotrophic protein in the adult brain, and BDNF plays a key role in hippocampal long-term potentiation, which is considered the foundation of learning and memory [32]. Moreover, aerobic exercise can increase the level of BDNF in peripheral blood, which can be absorbed by the brain tissue, thereby protecting the nerve and improving cognition [14, 33, 34]. Our study found that TUG1 can bind to BDNF and negatively regulates its expression. Meanwhile, we found that the overexpression of TUG1 reversed the improvement of the aerobic exercise on the cognitive ability and hippocampal apoptosis of VCI mice through regulating BDNF. These results indicated that the aerobic exercise alleviates VCI in part by regulating TUG1/BDNF.

\section{Conclusions}

In conclusion, our findings indicated that the TUG1/ BDNF axis participates in the aerobic exercise-alleviated VCI by reducing hippocampal neuronal apoptosis. 


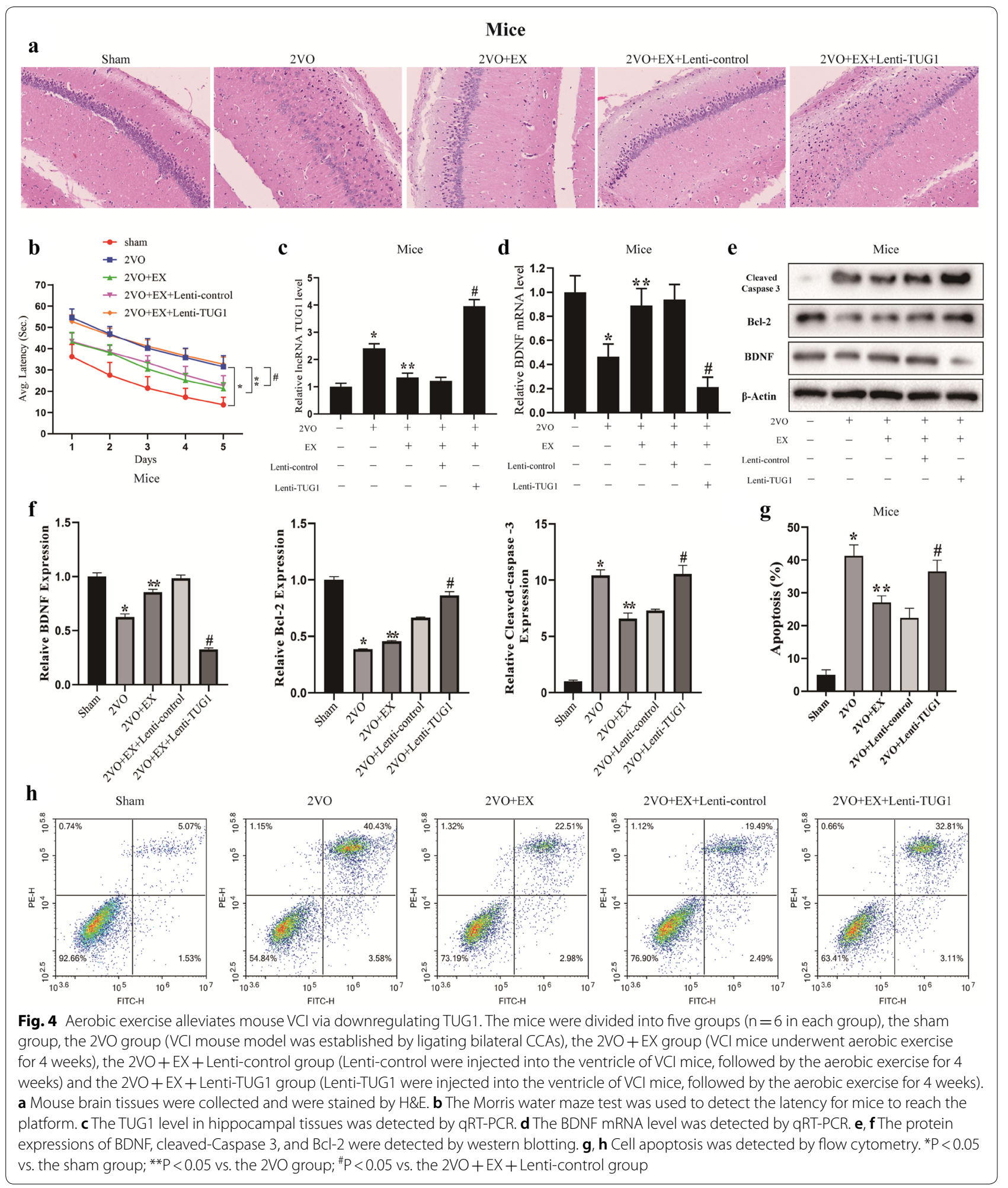

\section{Abbreviations}

VCI: Vascular cognitiveimpairment; qRT-PCR: Quantitativereal-time PCR; TUG1:Taurine upregulatedgene 1; OGD: Oxygen and glucose deprivation; BDNF: Brain-derived neurotrophicfactor; RIP: RNAimmunoprecipitation; CCA: Common carotid arteries; MTT:
3-(4,5-dimethylthiazol-2-yl)-2,5-diphenyl-2H-tetrazol-3-ium bromide; PBS: Phosphate buffersaline; IncRNAs: Long non-coding RNAs.

\section{Acknowledgements}

Not applicable. 


\section{Authors' contributions}

JW and YN performed the experiments, analyzed the data and wrote the paper, and they contributed equally to this work and were regarded as co-first authors; HT and MX contributed significantly to analysis and manuscript preparation; CW contributed to the conception of the study. All authors read and approved the final manuscript.

\section{Funding}

This study was funded by the Natural Science Foundation of China (No. 81802241).

\section{Availability of data and materials}

All data generated or analyzed during this study are included in this published article.

\section{Ethics approval and consent to participate}

Approval was received from the Tianjin Medical University General Hospital. Consent was obtained from the patient at the time of investigations. The animal experimental procedures were approved by the Animal Ethical Committee of the Tianjin Medical University General Hospital.

\section{Consent to publish}

Not applicable.

\section{Competing interests}

All authors declare that they have no conflict of interest.

\section{Author details}

${ }^{1}$ Department of Physical and Rehabilitation Medicine, Tianjin Medical University General Hospital, No. 154 Anshan Road, Peace District, Tianjin 300070, People's Republic of China. ${ }^{2}$ Department of Neurophysiology, Tianjin Medical University General Hospital, Tianjin 300070, China. ${ }^{3}$ Department of Medical Imaging, Tianjin Medical University General Hospital, Tianjin 300070, China.

Received: 5 July 2020 Accepted: 4 November 2020

\section{Published online: 19 November 2020}

\section{References}

1. van der Flier WM, Skoog I, Schneider JA, Pantoni L, Mok V, Chen CLH, Scheltens P. Vascular cognitive impairment. Nat Rev Dis Primers. 2018;4:18003

2. Gorelick PB, Counts SE, Nyenhuis D. Vascular cognitive impairment and dementia. Biochim Biophys Acta. 2016;1862:860-8.

3. Liu-Ambrose T, Best JR, Davis JC, Eng JJ, Lee PE, Jacova C, Boyd LA, Brasher PM, Munkacsy M, Cheung W, Hsiung GR. Aerobic exercise and vascular cognitive impairment: a randomized controlled trial. Neurology. 2016;87:2082-90

4. Ngandu T, Lehtisalo J, Solomon A, Levälahti E, Ahtiluoto S, Antikainen R, Bäckman L, Hänninen T, Jula A, Laatikainen T, et al. A 2 year multidomain intervention of diet, exercise, cognitive training, and vascular risk monitoring versus control to prevent cognitive decline in at-risk elderly people (FINGER): a randomised controlled trial. Lancet. 2015;385:2255-63.

5. Barnes JN. Exercise, cognitive function, and aging. Adv Physiol Educ 2015;39:55-62.

6. Batista PJ, Chang HY. Long noncoding RNAs: cellular address codes in development and disease. Cell. 2013;152:1298-307.

7. Zhang L, Luo X, Chen F, Yuan W, Xiao X, Zhang X, Dong Y, Zhang Y, Liu Y. LncRNA SNHG1 regulates cerebrovascular pathologies as a competing endogenous RNA through HIF-1a/VEGF signaling in ischemic stroke. J Cell Biochem. 2018;119:5460-72.

8. Zhang X, Tang X, Liu K, Hamblin MH, Yin KJ. Long noncoding RNA Malat1 regulates cerebrovascular pathologies in ischemic stroke. J Neurosci. 2017:37:1797-806.

9. Su Q, Liu Y, Lv XW, Ye ZL, Sun YH, Kong BH, Qin ZB. Inhibition of IncRNA TUG1 upregulates miR-142-3p to ameliorate myocardial injury during ischemia and reperfusion via targeting HMGB1- and Rac1-induced autophagy. J Mol Cell Cardiol. 2019;133:12-25.

10. Guo C, Qi Y, Qu J, Gai L, Shi Y, Yuan C. Pathophysiological functions of the IncRNA TUG1. Curr Pharm Des. 2020;26:688-700.
11. Zhang L, Cheng H, Yue Y, Li S, Zhang D, He R. TUG1 knockdown ameliorates atherosclerosis via up-regulating the expression of miR-133a target gene FGF1. Cardiovasc Pathol. 2018;33:6-15

12. Johnson R. Long non-coding RNAs in Huntington's disease neurodegeneration. Neurobiol Dis. 2012;46:245-54.

13. Chen KW, Chen L. Epigenetic regulation of BDNF gene during development and diseases. Int J Mol Sci. 2017;18:571.

14. Kennedy G, Hardman RJ, Macpherson H, Scholey AB, Pipingas A. How does exercise reduce the rate of age-associated cognitive decline? A review of potential mechanisms. J Alzheimers Dis. 2017;55:1-18.

15. Niu Y, Wan C, Zhou B, Wang J, Wang J, Chen X, Li R, Wang X, Liu W, Wang $Y$. Aerobic exercise relieved vascular cognitive impairment via NF-kB/miR503/BDNF pathway. Am J Transl Res. 2018;10:753-61.

16. Chen Hua YS. Pioglitazone up-regulates MALAT1 and promotes the proliferation of endothelial progenitor cells by increasing c-Myc expression in type 2 diabetes mellitus. Aging Pathobiol Ther. 2020;2:38-44.

17. Langdon KD, Granter-Button S, Harley CW, Moody-Corbett F, Peeling J, Corbett D. Cognitive rehabilitation reduces cognitive impairment and normalizes hippocampal CA1 architecture in a rat model of vascular dementia. J Cereb Blood Flow Metab. 2013;33:872-9.

18. Bae JY. Aerobic exercise increases meteorin-like protein in muscle and adipose tissue of chronic high-fat diet-induced obese mice. Biomed Res Int. 2018;2018:6283932.

19. Snow WM, Pahlavan PS, Djordjevic J, McAllister D, Platt EE, Alashmali S, Bernstein MJ, Suh M, Albensi BC. Morris water maze training in mice elevates hippocampal levels of transcription factors nuclear factor (Erythroid-derived 2)-like 2 and Nuclear Factor Kappa B p65. Front Mol Neurosci. 2015;8:70.

20. Nunez J. Morris water maze experiment. J Vis Exp. 2008;19:e897.

21. D'Hooge R, De Deyn PP. Applications of the Morris water maze in the study of learning and memory. Brain Res Brain Res Rev. 2001;36:60-90.

22. ladecola C, Duering M, Hachinski V, Joutel A, Pendlebury ST, Schneider JA, Dichgans M. Vascular cognitive impairment and dementia: JACC Scientific Expert Panel. J Am Coll Cardiol. 2019;73:3326-44.

23. Gorelick PB, Scuteri A, Black SE, Decarli C, Greenberg SM, ladecola C, Launer LJ, Laurent S, Lopez OL, Nyenhuis D, et al. Vascular contributions to cognitive impairment and dementia: a statement for healthcare professionals from the american heart association/american stroke association. Stroke. 2011;42:2672-713.

24. Ahlskog JE, Geda YE, Graff-Radford NR, Petersen RC. Physical exercise as a preventive or disease-modifying treatment of dementia and brain aging. Mayo Clin Proc. 2011:86:876-84.

25. Duncombe J, Kitamura A, Hase Y, Ihara M, Kalaria RN, Horsburgh K. Chronic cerebral hypoperfusion: a key mechanism leading to vascular cognitive impairment and dementia. Closing the translational gap between rodent models and human vascular cognitive impairment and dementia. Clin Sci (Lond). 2017;131:2451-68.

26. Koizumi K, Hattori Y, Ahn SJ, Buendia I, Ciacciarelli A. Apoe4 disrupts neurovascular regulation and undermines white matter integrity and cognitive function. Nat Commun. 2018;9:3816

27. Kalaria RN, Akinyemi R, Ihara M. Stroke injury, cognitive impairment and vascular dementia. Biochim Biophys Acta. 2016;1862:915-25.

28. Sun M, Shen X, Ma Y. Rehmannioside $A$ attenuates cognitive deficits in rats with vascular dementia (VD) through suppressing oxidative stress, inflammation and apoptosis. Biomed Pharmacother. 2019;120:109492.

29. Erickson KI, Voss MW, Prakash RS, Basak C, Szabo A, Chaddock L, Kim JS, Heo S, Alves H, White SM, et al. Exercise training increases size of hippocampus and improves memory. Proc Natl Acad Sci USA. 2011;108:3017-22.

30. Öhman H, Savikko N, Strandberg TE, Pitkälä KH. Effect of physical exercise on cognitive performance in older adults with mild cognitive impairment or dementia: a systematic review. Dement Geriatr Cogn Disord. 2014;38:347-65.

31. Foubert-Samier A, Flicker L. Aerobic exercise: a possible therapy for vascular cognitive impairment. Neurology. 2016;87:2072-3.

32. Lu B, Nagappan G, Lu Y. BDNF and synaptic plasticity, cognitive function, and dysfunction. Handb Exp Pharmacol. 2014;220:223-50.

33. Rasmussen P, Brassard P, Adser H, Pedersen MV, Leick L, Hart E, Secher NH, Pedersen BK, Pilegaard $\mathrm{H}$. Evidence for a release of brain-derived neurotrophic factor from the brain during exercise. Exp Physiol. 2009;94:1062-9. 
34. Knaepen K, Goekint M, Heyman EM, Meeusen R. Neuroplasticity-exerciseinduced response of peripheral brain-derived neurotrophic factor: a systematic review of experimental studies in human subjects. Sports Med. 2010;40:765-801.

\section{Publisher's Note}

Springer Nature remains neutral with regard to jurisdictional claims in published maps and institutional affiliations.
Ready to submit your research? Choose BMC and benefit from:

- fast, convenient online submission

- thorough peer review by experienced researchers in your field

- rapid publication on acceptance

- support for research data, including large and complex data types

- gold Open Access which fosters wider collaboration and increased citations

- maximum visibility for your research: over 100M website views per year

At BMC, research is always in progress.

Learn more biomedcentral.com/submissions 